\title{
Mutational Activation of ras Genes is Absent in Pediatric Osteosarcoma
}

\author{
F. Antillón-Klüssmann, M. García-Delgado, I. Villa-Elízaga, and L. Sierrasesúmaga
}

From the Department of Pediatrics (E. A.-K., I. V.-E., L. S.), Clínica Universitaria, School of Medicine, Universidad de Navarra, Pamplona; Department of Genetics (M. G.-D.), School of Science, Universidad de Navarra, Pamplona, Spain.

Address reprint requests to: F. Antillón-Klüssmann

Department of Pediatrics, Clínica Universitaria, School of Medicine, Universidad de Navarra, Apdo. 192, Pamplona E 31080, Spain.

\begin{abstract}
Activation of ras oncogenes is found in human cancers; overall it is observed in $15 \%$ of all neoplasms. The purpose of this study was to assess the extent of involvement of ras oncogenes in osteosarcoma. Tumor samples from a series of 49 pediatric patients diagnosed with osteosarcoma and treated at our institution were evaluated. Paraffinembedded tumor samples from diagnostic biopsies, from tumor en bloc resection tissue after neoadjuvant chemotherapy, and samples from metastases were examined in search of point mutations in $\mathrm{H}, \mathrm{K}$, and N-ras genes at codons 12 and 61 by means of polymerase chain reaction (PCR), slot-blotting, and radioactive labeled specific DNA probes. A total of 92 archival samples were studied. No point mutations activating these genes were found. These findings suggest that the activation by point mutations at codons 12 and 61 of the $\mathrm{H}, \mathrm{K}$, and N-ras genes does not play a role in the pathogenesis of human osteosarcoma. Since no point mutations in codons 12 and 61 were detected, it was not possible to establish any correlation between the ras genes and clinical or histologic findings.
\end{abstract}




\section{INTRODUCTION}

The ras family includes three oncogenes: K-ras derived from the Kirsten sarcoma virus, $\mathrm{H}$-ras from Harvey sarcoma virus, and $\mathrm{N}$-ras from a neuroblastoma. These genes encode highly related proteins of 189 amino acids generically known as p21 that are thought to control mechanisms of cell growth and differentiation. Mutated ras proteins have lost the ability to become inactivated and thus they stimulate growth or differentiation autonomously $[1,2]$. Sequence analyses have demonstrated the presence of point mutations in the ras oncogenes. These point mutations have been confirmed to codons 12,13 , and 61 in human neoplasia [3].

The ras oncogene family occupies a prominent position among the oncogenes involved in the pathogenesis of human cancer for several reasons: activation can be detected reliably and conveniently in a large number of human cancers. Single sections of routinely fixed and paraffin-embedded tumor biopsies are enough to provide the required DNA for polymerase chain reaction (PCR) and the amplified DNA can be tested for activating point mutations [4]. Activating ras mutations can be found in as many as $15-20 \%$ of unselected human tumors. The highest incidence is found in adenocarcinomas of the pancreas $(90 \%)$, colon $(50 \%)$, and lung $(30 \%)$, in thyroid tumors (50\%), and in myeloid leukemia (30\%) [3]. Nevertheless, no conclusive evidence has been found regarding the role of ras gene mutation in osteosarcoma. Cui and coauthors [5] have reported the absence of mutational activation of the K-ras gene in codons 12 and 61 in 18 tumor samples corresponding to 18 patients.

The purpose of this study was to assess the extent of involvement of mutational activation of the H-ras, K-ras, and N-ras genes in codons 12 and 61 in pediatric osteosarcoma and its possible relationship to prognosis, histopathologic features, and pathogenesis.

\section{STUDY DESIGN}

\section{Patients}

Forty-nine pediatric patients diagnosed with high-grade osteosarcoma [6] treated at the Pediatric Oncology Unit of our institution and from whom paraffin blocks were available from the Department of Pathology were included in the study. Biopsies were performed between 1983 and 1992. The number of biopsies from each patient varied from 1 to 5 . A total of 92 samples were analyzed.

\section{Pathologic Selection}

Hematoxylin-eosin-stained sections of each biopsy were examined microscopically to confirm the diagnosis and to select the sample with the greatest fraction of malignant cells. Bone samples were fixed with $10 \%$ buffered formalin for a maximum of 24 hours, and then decalcified with decalcificant solution (85\% formic acid, 35\% chlorhydric acid, and water up to final volume) during 4-7 days, washed in $\mathrm{H}_{2} \mathrm{O}$, and finally included in paraffin. The decalcifying solution was changed every day. 


\section{PCR and Probe Hybridization}

Tissue sections were deparaffinized as described by Rogers [7]. Primer-pair sequences used are as previously described [8] and synthetic oligonucleotide probes are shown in Table 1.

These primers and probes were synthesized using an automatic DNA synthesizer (Applied Biosystems 391 DNA Synthesizer). PCR primers were 20mer oligonucleotides complementary to sequences flanking codons 12 and 61 of $\mathrm{H}-, \mathrm{K}-$, and N-ras. PCR DNA amplification was performed as described [9]. Briefly, $2 \mu 1$ of the deparaffinized product were amplified in a reaction mixture in a final volume of $100 \mu 1$ which contained 100 pmol of each primer, 2.5 units of Taq DNA polymerase (Promega), 0.4 $\mathrm{mM}$ of each dNTP, $5 \mu \mathrm{l}$ of PCR $10 \mathrm{x}$ buffer $(500 \mathrm{mM} \mathrm{KCl}, 100 \mathrm{mM}$ Tris-HCl pH 9, and $1 \%$ triton $\mathrm{X}-100$ ), and $1.5 \mathrm{mM} \mathrm{MgCl}$. All the samples were covered with 2 drops of mineral oil and the reaction was per-formed in an automated thermocycler (Hybaid Thermal Cycler). Forty cycles of amplification were performed $\left(30 \mathrm{sec} / 94^{\circ} \mathrm{C}, 1\right.$ $\mathrm{min} / \mathrm{Tm}-5^{\circ} \mathrm{C}, 2 \mathrm{~min} / 72^{\circ} \mathrm{C}$ ). The success of the PCR was assessed by running $20 \mu 1$ of the product on a $1 \%$ agarose: $3 \% \mathrm{NuSieve}$ gel and visualizing the product as a $112-115$ base-pair band after staining with ethidium bromide (Fig. 1).

Ten microliters of TE buffer, $\mathrm{pH} 8$, were added to $10 \mu \mathrm{l}$ of the amplified product. DNA was denatured by heating the sample at $95^{\circ} \mathrm{C}$ for $5 \mathrm{~min}$. Forty microliters of SSC $20 \mathrm{x}$ were added and then applied to a Zeta-probe nylon filter (Bio Rad) under vacuum with a Bio-dot-SF apparatus (Bio-Rad). Duplicate filters were prepared and the DNA was fixed by baking. The 19 mer probes were labeled at the $5^{\prime}$ end using $y-{ }^{32}$ PdATP (Amersham) by means of T4 polynucleotide kinase (Boehringer) and purified through a Elutip-D column. Filters were prehybridized for 3 hours at $56^{\circ} \mathrm{C}$ in $3 \mathrm{M}$ tetramethylammonium chloride/50 mM Tris-HCL pH 7.5/2 mM EDTA/0.3\% SDS/denatured sonicated herring sperm $(100 \mu \mathrm{g} / \mathrm{m} 1) / 5 \quad \mathrm{x}$ Denhardt's solution. Approximately $1 \mathrm{pmol}$ of probe $\left(1 \times 10^{6} \mathrm{cpm} / \mathrm{ml}\right)$ was then added and hybridization continued at the same temperature for 12 hours. Filters were washed once in 2 x SSPE and $0.1 \%$ SDS for 10 minutes at room temperature and then in $3 \mathrm{M}$ tetramethylammonium chloride hybridization buffer minus carrier DNA and Denhardt's for $10-15$ minutes at $59^{\circ} \mathrm{C}$. Finally, the filters were autoradiographed at $-70^{\circ} \mathrm{C}$ (Fuji Xray film) using intensifying screens.

\section{RESULTS}

\section{Clinical Data}

A total of 92 archival samples corresponding to 49 patients were studied. Twenty biopsies were obtained at the time of diagnosis, 39 bone samples from en bloc resection after neoadjuvant chemotherapy, 22 metastasis samples (20 lung metastasis, one kidney metastasis, one brain metastasis), nine biopsies from local relapse, and one bone sample after amputation. Only one biopsy was available from 24 patients, two biopsies from 13, three samples from seven, four samples from four, and five samples from one patient. Twenty-five of the 49 patients were females and 24 were males. The age at diagnosis varied between 5 and 21 years (mean 13.86). The site of the primary lesion at diagnosis 
was femur 25, tibia 17, humerus three, fibula one, radius one, pelvis one, and calcaneum one. Forty-four patients were in stage IIB and five were in stage IIIB according to the Enneking classification [10]. Five patients had lung disease at diagnosis, five developed pulmonary metastasis during treatment, and 11 developed it after chemotherapy. Primary site histologic subtypes were the following: 32 osteoblastic osteosarcomas, nine chondroblastic osteosarcomas, six fibroblastic osteosarcomas, one telangiectasic osteosarcoma and one small cell osteosarcoma [12]. The degree or tumor destruction degree after initial treatment with preoperative chemotherapy was 25 patients with $<90 \%$ necrosis, 19 with $\geq 90 \%$, and unknown in five cases (two patients underwent limb amputation at other centers, and in three of them this was not evaluated) [13, 14]. Thirty-three patients remain alive (67.3\%), 15 died (30.6\%), and one was lost to follow up $(2 \%)$. Twelve patients died of disease progression, one of sepsis due to an episode of severe granulocytopenia secondary to cytostatic drugs, one due to severe bilateral pneumothorax after surgery, and one developed a second tumor (ALL) 2 years after treatment.

The total actuarial survival rate of the patients is $67.12 \pm 8.7 \%$ at 9 years of follow-up and the actuarial survival rate free of disease is $58 \% \pm 8.4 \%$ at 9 years of follow-up.

\section{Laboratory Data}

H-ras-12; DNA Amplification. The amplification product could be visualized in 43 samples (46.7\%). Six normal DNA controls were amplified successfully and no amplification was detected in negative controls.

Specific Probe Hybridization. Positive signals for H-ras-12- 12 wild probe were observed in $43(100 \%)$ tumoral samples with amplification, in $24 / 49(49 \%)$ of the samples in which amplification was not observed, and in normal DNA controls. No signals were observed in negative controls.

No positive signals were observed in the tumor samples for probes H-ras-12-13 and $\mathrm{H}$ ras-12-14.

H-ras-61; DNA Amplification. The amplification product could be visualized in 34 samples (37\%). Six normal DNA controls were successfully amplified and no amplification was observed in negative controls.

Specific Probe Hybridization. Positive signals for H-ras-61-15 wild probe were observed in $34(100 \%)$ tumoral samples with amplification, in 13/58 (22\%) of the samples in which amplification was not observed, and in five of six normal DNA controls. No signals were observed in negative controls.

No positive signals were observed in the tumor samples for probes H-ras-61-17 and $\mathrm{H}-$ ras-61-18.

K-ras-12; DNA Amplification. The amplification product could be visualized in 29 samples (31.5\%). Six normal DNA controls were successfully amplified and no amplification was observed in negative controls. 
Specific Probe Hybridization. Positive signals for K-ras-12-5 wild probe were observed in 28/29 (97\%) tumoral samples with amplification, in 10/63 (16\%) of the samples in which amplification was not visualized, and in normal DNA controls. No signals were observed in negative controls.

No positive signals were observed in the tumor samples for probes K-ras-12-6 and Kras-12-7.

K-ras-61; DNA Amplification. The amplification product could be visualized in 26 samples (28.6\%). Four of six normal DNA controls were successfully amplified and no amplification was observed in negative controls.

Specific Probe Hybridization. Positive signals for K-ras-61-8 wild probe were observed in $24 / 26(92.3 \%)$ tumoral samples with amplification, in 19/65 (29\%) of the samples in which amplification was not visualized, and in normal DNA controls. No signals were observed in negative controls (Fig. 2).

No positive signals were observed in the tumor samples for probes K-ras-61-10 and Kras-61-11.

N-ras-12; DNA Amplification. The amplification product could be visualized in 46 samples (50\%). Six normal DNA controls were successfully amplified and no amplification was observed in negative controls. Positive controls with known mutations were also amplified (Table 2).

Specific Probe Hybridization. Positive signals for N-ras12-GLY wild probe were observed in 45/46 (98\%) tumoral samples with amplification, in 39/46 (85\%) of the samples in which amplification was not visualized, and in normal DNA controls. No signals were observed in negative controls (Fig. 3).

No positive signals were observed in the tumor samples for probes N-ras-12-ARG, Nras-12-CYS, N-ras-12-ASP, and N-ras-12-VAL. Sample 12 D had positive signals with probes N-ras-12-SER and N-12-ras-ALA. This sample was sequenced, the sequence being normal. Samples TH-p1 and p33A with known mutations used as positive controls gave positive signals for probe N-ras-12-ASP (Fig. 4).

N-ras-61; DNA Amplification. The amplification product could be visualized in 21 samples (22.8\%). Six normal DNA controls were successfully amplified and no amplification was observed in negative controls.

\section{Specific Probe Hybridization}

Positive signals for N-ras-61-1 wild probe were observed in 17/21 (81\%) tumoral samples with amplification, in 10/71 (14\%) of the samples in which amplification was not visualized, and in normal DNA controls. No signals were observed in negative controls.

No positive signals were observed in the tumor samples for probes N-ras-61-2, N-ras61-3, and N-ras-61-4. 


\section{DISCUSSION}

The main goal of this study was to assess comprehensively the frequency of activating ras mutations in pediatric osteosarcoma. There was a sufficient number of cases studied and they fairly represent the histologic subtypes with different biologic behavior. The approach we used, involving PCR-oligonucleotide hybridization analysis, allows the screening of many cases and, with nucleotide sequence analysis, provides qualitative data on the type of mutation in positive cases as well as conclusive identification of the negative ones.

Although it has been reported that fixation in 10\% buffered formalin for 48 hours or less does not affect the efficiency of amplification, we did not achieve amplification in many of the samples (from 21/92 successful amplifications in codon N-61 to 46/92 successful amplifications in codon $\mathrm{N}-12$ ). This low yield is probably due to three main reasons. In the first place, this may be attributed to formaldehyde fixation. Formaldehyde, as a $10 \%$ aqueous solution, is the most commonly used fixative in routine histopathologic practice. It is a non-coagulative fixative that acts by forming cross-links between protein molecules. This cross-linking of proteins forms a gel, maintaining the in vivo relationship of intracellular components. However, formalin is not a good fixative of DNA. At temperatures usually used for fixation (room temperature) no uncoiling of DNA occurs. The poor fixation of DNA by formalin at room temperatures causes loss of DNA into the fixative solution by leaching [15]. In the second place, the severe decalcification protocol of bone samples in strong acids for more than 4 days could also affect the quality of the DNA in the tumor samples. The last but probably most important reason for the low yield in the amplification reactions was the high degree of tumor necrosis in most of the samples induced by intra-arterial chemotherapy with cisplatinum. Twenty-five of the forty-nine patients had $\geq 90 \%$ necrosis after tumor en bloc resection. Nineteen had $\leq 90 \%$ necrosis (all of them had a necrosis of $60-90 \%$ ), and unknown in five cases.

Nevertheless, even if the amplification product was not visualized on agarose-NuSieve gels, many samples had positive signals on specific probe hybridization. We successfully analyzed 72 samples for codon H-12, 47 for codon H-61, 41 for codon K12, 47 for codon K-61, 91 for codon N-12, and 31 for codon N-61-ras. Point mutations were not found in any of these codons. These findings suggest that the activation by point mutations at codons 12 and 61 of the $\mathrm{H}, \mathrm{K}$, and N-ras genes does not play a role in the pathogenesis of human osteosarcoma. This is consistent with a previous report which only analyzed the K-ras gene at codons 12 and 61 in 18 samples [5]. Since no point mutations of ras genes were detected, it is not possible to establish any correlation between the ras genes and clinical or histologic findings.

\section{ACKNOWLEDGEMENTS}

We are indebted to Dr. J.W.G. Janssen from the University of Ulm, Germany, for kindly providing N-ras-positive DNAs, to Ana Patiño García for her help in the preparation of this manuscript, and to Fundación Echébano for financial support. 


\section{REFERENCES}

1. Barbacid M (1987): ras Genes. Ann Rey Biochem 56:779-827.

2. Barbacid M (1990): ras oncogenes: their role in neoplasia. Eur J Clin Invest 20:225-235.

3. Bos JL (1989): ras oncogenes in human cancer: a review. Cancer Res 49:46824689.

4. Rodenhius S (1992): ras and human tumors. Sem Cancer Biol 3:241-247.

5. Cui LX, Oka T, Dobashi Y, Ishida T, Machimani L (1991): Mutational activation of K-ras gene is absent in human osteosarcoma. Med Sci Res 19:697698.

6. Unni KK, Dahlin DC (1984): Grading of bone tumors. Sem Diagn Pathol 1:165172.

7. Rogers BB, Alpert LC, Hine EA, Buffone GJ (1990): Analysis of DNA in fresh and fixed tissue by polymerase chain reaction. Am J Pathol 136:541-548.

8. Neri A, Knowles DM, Greco A, McCormick F, Dalla-Favera R (1988): Analysis of ras oncogene mutations in human lymphoid malignancies. Proc Natl Acad Sci USA 85:9268-9272.

9. Saiki RK, Scharf S, Faloona F, Mullis KB, Horn GT, Erlich HA, Arnhein N (1985): Enzymatic amplification of $\beta$ globin genomic sequences and restriction site analysis for diagnosis of sickle cell anemia. Science 230:1350-1354.

10. Enneking WF, Spanier SS, Goodman MA (1980): A system for the surgical staging of musculoskeletal sarcoma. Clin Orthop 153:106-120.

11. Dahlin DC (1978): Osteosarcoma of bone and a consideration of prognostic variables. Cancer Treat Rep 60:189-192.

12. Martin SE, Dwyer A, Kissanne JM, Costa J (1982): Small-cell osteosarcoma. Cancer 50:990-996.

13. Winkler K, Beron G, Delling G. Heise U, Kabish H, Purfürst C, Berger J, Ritter J, Jürgens H, Gerein V, Graf N, Russe W, Gruemayer E, Ertelt W, Kotz R, Preuserr P, Prindull G, Brandeis W, Landbeck G (1988): Neoadjuvant chemotherapy of osteosarcoma: results of a randomized cooperative trial (COSS-82) with salvaga chemotherapy based on histologic tumor response. J Clin Oncol 6:329-337.

14. Picci P, Bacci G, Campanacci M, Gasparini M, Pilotti S, Cerasoli S, Bertoni F, Guerra A, Campanna R, Albisinni U, Galletti S, Gherlinzoni F, Calderoni P, Sudanesa A, Balbini N, Bernini M, Jaffe N (1985): Histologic evaluation of necrosis in osteosarcoma induced by chemotherapy. Regional mapping of viable and noviable tumor. Cancer 56:1515-1521.

15. Jackson DP, Lewis FA, Taylor GR, Boylston AW, Quirke P (1990): Tissue extraction of DNA and RNA and analysis for the polymerase chain reaction. $\mathrm{J}$ Clin Pathol 43:499-504. 
Table 1. DNA probes used for the detection of point mutations

\begin{tabular}{|c|c|}
\hline N-ras-12 GLY wild & 5'-GTT-GGA-GCA-GGT-GGT-GGT-G-3' \\
\hline N-12-SER & aGT \\
\hline $\mathrm{N}-12-\mathrm{ARG}$ & cGT \\
\hline $\mathrm{N}-12-\mathrm{CYS}$ & tGT \\
\hline N-12-ALA & GcT \\
\hline $\mathrm{N}-12-\mathrm{VAL}$ & GtT \\
\hline N-ras-61-1 wild & 5'-ACA-GCT-GGA-CAA-GAA-GAG-T-3' \\
\hline $\mathrm{N}-61-2$ & nAA \\
\hline $\mathrm{N}-61-3$ & $\mathrm{CnA}$ \\
\hline $\mathrm{N}-61-4$ & CAn \\
\hline K-ras-12-5 wild & 5'-GGT-GGA-GCT-GGT-GGC-GTA-G-3' \\
\hline K-12-6 & nGT \\
\hline $\mathrm{K}-12-7$ & GnT \\
\hline K-ras-61-8 wild & 5-ACA-GCA-GGT-CAA-GAG-GAG-G-3' \\
\hline K-61-9 & nAA \\
\hline K-61-10 & $\mathrm{CnA}$ \\
\hline K-61-11 & CAn \\
\hline H-ras-12-12 wild & 5'-GTG-GGC-GCC-GGC-GGT-GTG-G-3' \\
\hline H-12-13 & nGC \\
\hline H-12-14 & $\mathrm{GnC}$ \\
\hline H-ras-61-15 wild & 5'-ACC-GCC-GGC-CAG-GAG-GAG-T-3' \\
\hline H-61-16 & CAn \\
\hline H-61-17 & $\mathrm{nAG}$ \\
\hline H-61-18 & $\mathrm{CnG}$ \\
\hline
\end{tabular}

Table 2. DNA controls with known mutations

\begin{tabular}{|l|c|c|}
\hline Sample & DNA concentration & Mutation \\
\hline Cell line THP-1 & $140 \mu / \mathrm{ml}$ & GGT > GAT (Asp) N-ros pos. 12 \\
\hline Patient 14A & $560 \mu / \mathrm{ml}$ & GGT > GAT (Asp) N-ros pos. 13 \\
\hline Patient 20A & $150 \mu / \mathrm{ml}$ & GGT > CGT (Asp) N-ros pos. 13 \\
\hline Patient 33A & $390 \mu / \mathrm{ml}$ & GGT > GAT (Asp) N-ros pos. 12 \\
\hline
\end{tabular}

